\title{
Enhancing Innovation Processes through the Application of Emotional Intelligence Skills
}

James D Hess*

Marketing Science Bio, University of Houston, USA

\begin{abstract}
Purpose: Little research has been contributed to how the behaviours associated with emotional intelligence may be practically applied to enhance both individual and group innovation processes. The purpose of this paper is to identify practical approaches to the application of emotional intelligence skills to the complexity of the innovation process. Additionally, the behaviours most often identified with emotional intelligence may be learned and applied in a practical manner to improve the overall quality of creative and innovative processes.
\end{abstract}

Design/Methodology/Approach: Goleman's and Boyatzis' et al. four essential elements of emotional intelligence and their associated 20 behavioural competencies are utilized to develop a methodology for the practical application of emotional intelligence skills to innovation. A series of questions, observations and action steps are outlined to improve emotional intelligence awareness, as well as the utilization of emotional intelligence skills to enhance innovation processes.

Findings: Organizations and individuals may benefit from the development and utilization of behaviours attributed to emotional intelligence. The practical application of emotional intelligence skills can enhance individual and group innovation processes and outcomes.

Originality/Value: The practical application of emotional intelligence skills becomes a strategy for the development of the individual's and organization's ability to assess the impact and consequences of innovation, while simultaneously improving the quality and effectiveness of the innovation process.

Keywords: Innovation/Creativity; Emotional intelligence skills; Practical approaches

\section{Category: Conceptual}

\section{Introduction}

The ability of public organizations, corporations and entities to continually create and innovate is dependent upon a multitude of intrinsic and extrinsic factors. While the management of extrinsic variables may be more difficult to control, the identification and management of human variables such as emotion and logic are pivotal in the effort to increase the quality of creativity and innovation processes $[1,2]$.

Creativity and innovation often hinge upon the ability to evaluate and solve complex problems, requiring both rational and emotional skills. In that vein, one of the most fascinating dichotomies in contemporary thought surrounding innovation is the apparent conflict between the roles of emotion and rationality. Stanovich and West [3] divided cognitive functions between those that were faster, effortless, implicit and emotional as compared to those that were slower, conscious, explicit and logical. The authors believed better solutions could be derived by shifting individuals from intuitive and emotional thinking to logical and rational thinking. Moreover, the authors concluded replacing intuition and emotion with more intensive data collection and analytical processes enabled the construction of linear models to produce relevant predictors. The suggestion here is that human beings will produce better results if we transform our cognitive functions to resemble those of an emotion-free microprocessor.

Conversely, there is an alternate research process proceeding in artificial intelligence to inject learned emotions into microprocessor driven problem solving. IBM is developing a cognitive computing processor to emulate the patterns of human thinking Bai [4]. Additionally, the MIT Artificial Intelligence Laboratory has developed an artificially intelligent machine that has defined elements of sensory and emotional systems Velasquez [5]. The computerized platform is capable of modelling six different emotions for decision-making: anger, [6] fear, distress/sadness, joy/happiness, disgust and surprise. Velasquez's premise based upon previous work Damasio [7] is that intuition and emotions play crucial roles in the ability to make smart, rational judgments.

Thus the ironic dichotomy of current thought is that some researchers believe human beings as innovators will reach better solutions when emotions are removed, and the mind is bent to perform more like a data-analyzing machine. Concomitantly, some researchers contend data-analyzing machines will make better decisions in complex circumstances when they are capable of utilizing intuition and emotions. So who is right? The author contends both are fundamentally correct, and that consistent with Simon's $[8,9]$ notion that emotion and rationality are inextricably linked, emotional intelligence can serve as the necessary bridge between the two. Moreover, the behaviours most often identified with emotional intelligence may be learned and applied in a practical manner to improve the overall quality of creative and innovative processes.

*Corresponding author: James D Hess, University of Houston, USA, Tel: 918561-8215; E-mail: jim.hess@okstate.edu

Received August 01, 2014; Accepted September 06, 2014; Published September 12, 2014

Citation: Hess JD (2014) Enhancing Innovation Processes through the Application of Emotional Intelligence Skills. Review Pub Administration Manag 2: 143. doi: 10.4172/2315-7844.1000143

Copyright: (c) 2014 Hess JD. This is an open-access article distributed under the terms of the Creative Commons Attribution License, which permits unrestricted use, distribution, and reproduction in any medium, provided the original author and source are credited. 
While emotional intelligence has been the subject of a significant amount of literature over the past two decades, ranging from debate over whether emotional intelligence is innate or learned, to the categorization of specific behaviours that define emotional intelligence, little has been contributed to how the behaviours associated with emotional intelligence may be practically applied to enhance both individual and group innovation. The purpose of this paper is to review relevant emotional intelligence literature and to identify practical approaches to the application of emotional intelligence skills to enhance the innovation process.

\section{Relevant Emotional Intelligence Research}

The definition of emotional intelligence and the context in which the term should be used has been a matter of debate in the literature over a number of years Mayer et al. and Thorndike [10,11] first coined the term "social intelligence" to describe the skills utilized in understanding and managing people. Later in 1940 Wechsler Bar-On [12] noted the influence of other factors on intelligent behaviour and posited that models of intelligence could not be complete until those factors were more fully understood. The term "emotional intelligence" was first used in the United States in a doctoral dissertation studying the acknowledgement and effects of emotion Payne [13]. This work was followed by an emotional intelligence model described by Salovey and Mayer [14] articulating emotions could enhance rationality and that individuals would be better served to work with, rather than against, their emotions. Bradberry and Greaves [15] noted emotional intelligence skills, when considered cumulatively, were vital in representing mental and behavioural functions of individuals beyond their native intelligence.

The bulk of the literature in emotional intelligence may be encapsulated in the description of three models: 1) ability model; 2) trait model and 3) mixed model. The ability model as described by Salovey and Grewal [16] posited that individuals have varied abilities to process and react to emotional circumstances and as a result develop adaptive behaviours to deal with social situations. The trait model proposed by Petrides et al. [17] was based upon the premise emotional intelligence represents a cluster of self perceptions operating at the lower levels of personality. This focus on behavioural dispositions relied heavily on self measurement and as such was more resistant to scientific calibration [17]. The mixed model was best characterized by Goleman's [18] description of emotional intelligence as a wide array of competencies and skills driving leadership performance. Goleman's model was based on the premise emotional competencies are not innate traits, but rather learned skills that may be developed and improved.

In a follow-up study Goleman [18] noted the very best corporate leaders, while diverse in their leadership styles, share in common the characteristics of self-awareness, self-regulation, motivation, empathy and social skill. These skills according to Goleman allow superb leaders to understand their own as well as others' emotional makeup well enough to move people to accomplish institutional objectives. Goleman's original work on emotional intelligence described the following essential elements or abilities: 1) knowing one's emotions; 2) managing emotions; 3 ) motivating oneself; 4) recognizing emotions in others and 5) handling relationships. Goleman's theory of emotional intelligence and its characteristic behaviours has been further refined to include both individual and organizational behaviours and outcomes. The more fully developed emotional intelligence model as described by Goleman and Boyatzis et al. refined the original five elements into four dimensions and further subdivided these characteristics into 20 behavioural competencies as outlined in the following table.

The literature addresses a number of issues regarding emotional intelligence and the world of work. Dulewicz et al. [20] discovered that emotional intelligence among managers correlated positively with the quality of work life and morale, and Brackett et al. [21] reported that low scores on emotional intelligence were associated with poor relations among peers. Similarly, Sue-Chan and Latham [22] conducted a study indicating there was a positive correlation between emotional intelligence and team playing behaviour, while Welch [23] proposed that teams exhibiting higher emotional intelligence were more likely to show initiative in dealing with organizational challenges and were more sensitive to change. Likewise, Rapisarda [24] concluded emotional intelligence competencies were positively correlated with cohesiveness among team members.

According to Sardo [25] workforces comprised of individuals that were more in touch with the emotions of others around them were better able to achieve higher organizational outcomes. In that same vein, Chaudhry and Usman [26] reported a high correlation between emotional intelligence and organizational citizenship behaviour. Langhorn [27] was able to show that managers who exhibited emotional intelligence were able to predict satisfaction among team members with a reasonable degree of accuracy. Hess and Bacigalupo [28] described how knowledge management organizations might utilize emotional intelligence behaviours as a development process to assist managers in the engagement of their knowledge workers.

A number of studies have identified emotional intelligence as a significant factor in job performance and effectiveness. Rosete and Ciarrochi [29] found a significant relationship between emotional intelligence and leadership effectiveness in a group of executives. Van Rooy and Viswesvaran [30] reported that levels of emotional intelligence had predictive value in performance outcomes. Similarly, Cavallo and Brienza [31] conducted a study of 300 managers at Johnson and Johnson and found superior job performers scored higher in all four emotional intelligence clusters (self awareness, self management, social awareness and relationship management). Luskin et al. [32] studied financial service advisors and found that after emotional intelligence competency training, job stress levels decreased and revenue performance measures increased. In a similar study Bachman et al. [33] that financial account officers with higher levels of emotional intelligence had higher levels of earnings goal attainment.

Emotional intelligence has been further related to the realm of employee stress and job satisfaction. Oginska-Bulik [34] reported a negative relationship between emotional intelligence and perceived stress in the workplace. Similarly, Dulewicz et al. [20] found a strong negative correlation between the emotional intelligence of managers and stress at work. Carmeli [35] concluded that emotional intelligence was negatively related to intentions to withdraw from the organization. Kernbach and Schutte's [36] study reported that service providers with higher levels of emotional intelligence experienced greater job satisfaction.

The domain of emotional intelligence has benefited from recent literature in the leadership and group dynamics disciplines. Taylor et al. [37] noted both aspiring and established leaders in the organizations they studied agreed the behaviours associated with emotional intelligence were characteristics of effective leaders and critical to the future success of aspiring leaders. The authors noted an additional function in established leaders described as organizational altruism 
or more specifically defined as an understanding of the institution and dedication to the institution's success. Wang and Haung [38] found that emotional intelligence and group cohesiveness were positively associated with transformational leadership. In detailing the relevance and efficacy of emotional intelligence, Antonakis et al. [39] concluded relationship approaches to leadership were inherently emotional, making emotional intelligence an integral part of the leadership process. Similarly, Dasborough and Ashkanasy [40] argued leader/member exchange relationship quality was enhanced through emotional intelligence of leaders, and Zhou and George [41] concluded emotional intelligence can enhance leadership within team settings.

Regarding the role of emotional intelligence in decision-making processes, Sevdalis et al. [42] noted that although empirical research has emphasized the relevance of emotions in decision-making processes, individual differences in the perception and experience of emotion have been largely overlooked. The authors concluded when people make decisions, they often think about the emotions the outcomes are likely to trigger. Further, Sevdalis et al. [42] outlined decisionmakers: 1) anticipate their emotions before a decision materialize; 2) experience them when they receive the outcomes of their decision and 3) recall them from memory when they contemplate past decisions (good or poor). Mellers et al. [43] concluded emotions people expect to experience or have experienced as a result of their decisions are important determinants of their current and future behaviour. Winter and Kuiper [44] noted individuals differ in systematic ways in how they experience emotions, how they differentiate among emotions and how much emotional information they can process. Hess and Bacigalupo [45] described how decision making processes may be enhanced through the application of emotional intelligence behaviours.

Addressing the role of emotional intelligence in problem solving and innovation processes, Salovey and Mayer proposed that individuals differ greatly in their ability to organize their emotions to address issues. The authors concluded positive mood enables a greater degree of flexibility in future planning and better preparation for making the most of future opportunities. Similarly, they claimed that a good mood is beneficial in creative thinking, as it increases an individual's ability for developing category organizing principles. Unfortunately, the reverse of these abilities has a tendency to hold true for individuals in negative moods.

The literature also suggests a differentiation in the effectiveness of emotional intelligence between individual and group tasks. Jordan and Troth [46] found that while no link between emotional intelligence and performance existed at the individual level when the task being performed was purely cognitive in nature, the same task transferred to a team setting introduced an emotional element requiring emotional intelligence skills. More specifically the authors concluded a team's overall level of emotional intelligence and the ability of team members to deal with their own emotions impacted performance. Druskat and Wolff [47], Jordan et al. [48] noted that teams comprised of members with higher levels of emotional intelligence will perform better on tasks than teams comprised of members exhibiting lower levels of emotional intelligence.

Addressing the role of emotional intelligence in creativity and innovation, Fenwick [49] found that emotion plays a pivotal role in employees' readiness to create and innovate. The author concluded a central motivator to fueling innovative learning was the perceived linkage of the innovation to a worthwhile social purpose. Park [50] hypothesized there was a correlation between certain experienced feelings related to engagement and involvement and the extent to which staff were able to be curious, resilient, creative, strategic and interdependent. Park concluded organizations are more likely to enhance creativity by focusing on the quality of their emotional environment. Suliman and Al-Shaikh [51] concluded emotional environments directly impact innovation, noting that conflicts employees face at work are likely to have a negative influence on their readiness to create and innovate. Yuvaraj and Srivastava [52] found that levels of managerial innovation were correlated to higher levels of emotional intelligence, implying that emotional intelligence should be an integral part of an organization's recruitment and development process.

\section{Emotional Intelligence Skills and Innovation}

While much of the literature has focused on the theoretical aspects of emotional intelligence, a significant gap exists in the practical application of these skills to innovation. Accepting the premise that emotional intelligence adds value to the individual and/or group innovation processes, the question arises how can it be practically applied to achieve that desired result? Organizations are continually faced with problems or circumstances that require innovation and creativity. Often these circumstances present themselves in the form of complex problems that cannot be easily solved and in some cases have negative impacts on some constituency even when they have been declared solved. Thus the consideration of the effect of innovative/ creative solutions on others should be an important element of the innovation process. While determining "who" will be most affected by innovations may be a more pragmatic function requiring rationality and logic, determining "how" the innovation will be interpreted and its subsequent effect on others requires the skills associated with emotional intelligence.

\section{Self awareness...Evaluating the role of the innovator}

Self awareness and its representative competencies of accurate self assessment and self confidence (Table 1) enable the emotionally intelligent innovator to determine his or her appropriate role in the innovation process $[1,2]$. Specifically, these skills enable innovators to determine if they have the requisite orientation to a problem and have enough self confidence to assess their own skills in comparison to others. Accordingly, these emotional intelligence skills create a decision path to determine who is the most appropriate person or group to consider, design and implement the best solution in any given innovation circumstance. Without emotional intelligence, innovators fail the first and most important decision, which is "who is the best innovator for this particular problem or circumstance?"

\section{Social awareness...Assessing the innovation environment}

The emotional intelligence skill of social awareness and its core competencies of empathy, service orientation and organizational awareness enable problem solvers to judge the impact of not only their solutions but also the manner in which those solutions are reached [1,2]. The best innovations or solutions are those that can be understood and accepted by the individuals most affected by the solution. Whether they are individuals or groups, innovators who practice the value of empathy can foresee the impact of their solutions before implementation [1] Likewise, exhibiting a servant philosophy can greatly enhance the quality of solutions. If innovators view those affected by innovations as customers who may be retained or lost, they are more likely to consider the outcomes and consequences of solutions [53]. Finally, it seems obvious being aware of the organization's culture, values and mores 


\begin{tabular}{|c|c|c|c|}
\hline Self Awareness & Social Awareness & Self-Management & Relationship Management \\
\hline $\begin{array}{l}\text { Self Confidence } \\
\text { Accurate Self Assessment }\end{array}$ & $\begin{array}{l}\text { Empathy } \\
\text { Service Orientation } \\
\text { Organizational Awareness } \\
\text { Empathy }\end{array}$ & $\begin{array}{l}\text { Self Control } \\
\text { Trustworthiness } \\
\text { Conscientiousness } \\
\text { Adaptability } \\
\text { Achievement Drive } \\
\text { Initiative }\end{array}$ & $\begin{array}{l}\text { Developing Others } \\
\text { Influence } \\
\text { Communication } \\
\text { Conflict Management } \\
\text { Leadership } \\
\text { Change Catalyst } \\
\text { Building Bonds and Teamwork } \\
\text { Collaboration }\end{array}$ \\
\hline
\end{tabular}

${ }^{*}$ Goleman [1] and Boyatzis et al. [2].

Table 1: Dimensions of Emotional Intelligence and Associated Behavioral Competencies*.

will enable the innovator to make a more rational judgment in the solution itself, as well as the process by which the solution is reached.

\section{Self management... Determining the motivations of innovation}

Self-management and its components of self-control, trustworthiness, conscientiousness, adaptability, achievement drive and initiative are arguably the most important emotional intelligence skills for innovators [1,2]. Controlling the impulse to solve every problem individually can sometimes fly in the face of the need to show initiative and achievement [53]. Additionally, in order for an innovator to gain moral authority on an issue, he or she must first be viewed as trustworthy by those most affected. Innovators can utilize self management skills to establish a consistent record of achievement, while simultaneously earning trust from both internal and external audiences.

In settings where the speed at which technical issues can be resolved or new products, applications or solutions can be made available is highly valued, the temptation is to avoid innovation processes which occupy valuable time. However, the emotionally intelligent innovator will evaluate the longer term consequences of losing trust among workers and teams when speed wins outs over participation [53]. Suppressing the need for personal achievement and relying on adaptability, the emotionally intelligent innovator or manager will assess the best innovation process for each circumstance and be conscientious in engaging the appropriate individuals and groups.

\section{Relationship management...Managing the innovation process}

As noted previously in Table 1, relationship management includes developing others, influence, communications, conflict management, leadership, change catalyst, building bonds and teamwork $[1,2]$. The enhancement of innovation processes is dependent upon the ability to effectively communicate desired outcomes, influence stakeholders and manage conflict. In both individual and group innovation processes, the ability to manage relationships is pivotal to success [54]. Even the best of innovations can have negative results if not properly communicated, including the proper articulation of innovation processes. Innovations that bring about fundamental change are fraught with potential conflict, regardless of the original intent of the change. The ability to manage that conflict is central to both the process and outcome of innovations, requiring innovators to exercise emotional skills while simultaneously attempting to steer necessary changes.

\section{Applying Emotional Skills to the Innovation Process Application of self awareness skills}

Applying these self awareness skills to innovation situations is a process that can be learned. The following questions, observations and action steps can serve as a practical guide for individuals and organizational leaders in innovation circumstances.

Is the potential innovator aware of his or her innovation skills and styles? The emotionally intelligent innovator will make an honest self assessment of skills and styles, noting the differences in his or her behaviours and abilities as compared to others.

Would others describe the innovator as inclusive or exclusive in creativity and/or innovation processes? The leadership styles as described by Vroom and Yetton [55] are useful here. The authors described a range of behaviours beginning with the pure autocratic style, to partial inclusion and pure delegation. While an innovator may describe himself or herself as more democratic or participatory, the more critical aspect is the perception of others. While it is not appropriate to be inclusive in every innovation process, the emotional intelligence function suggests it is important to communicate to others when and why inclusive or exclusive methodologies are utilized.

Is the innovator confident in his or her innovation, creativity and problem solving skills? Tsai and Young [56] concluded that fear makes individuals second-guess themselves and abandon support for efforts that have gone even slightly off track. The emotionally intelligent innovator must exude confidence in his or her style. Being self aware also implies acknowledging one's weaknesses and having the confidence to recognize the strengths of others in the innovation process. Self awareness also includes the skill of recognizing the impact of one's styles and behaviours on others. The emotionally intelligent innovator views every solution as a potential opportunity to develop themselves as well as those around them.

Innovation Action Steps: Consider the steps most often utilized in one's natural style. Is there a tendency to reach first for the emotional elements of a solution circumstance, or conversely, to reach for the rational analysis components? Innovators should also ask themselves whether they are inclusive or exclusive in the innovation process. Given the human tendency to avoid areas of perceived weakness, it is important to identify the most uncomfortable aspects of the innovation process and will oneself to spend more time in that domain in order to dispel the discomfort. 


\section{Application of social awareness skills}

In assessing and developing social awareness skills, innovators might consider the following questions, practical observations and action steps.

What individuals, groups or constituents will be most affected by the innovation? Social awareness implies the innovator has adequately contemplated the impact and consequences of the innovation before it is implemented. This emotional intelligence skill requires the innovator to play out scenarios of solutions to determine both their short and long-term consequences and effects Huy [57].

Should those most impacted by a circumstance requiring creativity/ innovation be involved in the innovation process? The skill of social awareness includes the skill of scanning the environment to determine if and when inclusion or exclusion is necessary or appropriate. Not all innovations are viewed positively, particularly those surrounding business processes. When contemplating an action, it is critical to determine whether those impacted by an innovative solution will receive the change more positively if they are involved in the innovation process.

What innovation processes are most appropriate given the culture and/or values of the organization? Being socially aware requires the innovator to assess the historical and cultural mores of the organization to determine appropriate actions. For example, if the culture of the organization is team oriented and participatory in nature, it would be important to design innovation processes consistent with those values.

How will the innovation process be viewed in retrospect? Emotionally intelligent innovation requires looking forward and backward simultaneously. Reliving past innovations through the lens of their impact assists the emotionally intelligent innovator in playing out the future of current contemplated actions.

Innovation Action Steps: In recalling an innovation that affected others negatively, reflect on the negative consequences experienced and how the solution made others feel. Now identify how the innovation process should have been executed. Identify an innovation within an organization that was inconsistent with the values and culture of the organization and note the values that were violated. Innovators can benefit by determining how the solution could have been handled to be more consistent with the values of the organization.

\section{Application of self management skills}

The following interrogatories and observations will enable innovators to establish or more fully develop their self-management emotional intelligence skill set.

Is the innovator merely focused on his or her pursuits or are they truly interested in achieving the best solution results? Emotionally intelligent innovators are characterized by their ability to suppress their own desires and interests for the common good.

Is the innovator focusing too much on the desire for a speedy result? Bazerman and Malhotra [58] noted that time pressures often lead innovators to bad judgments. Patience is pivotal in achieving the desired solution outcome.

How may an innovation process be utilized to build trust among the appropriate constituents? Mayer and Caruso [59] noted that leaders high in emotional intelligence build real social fabric within an organization, as well as between the organization and those it serves. Accordingly, emotionally intelligent innovations are those that are grounded in the feelings, values and beliefs of the organization. Innovations that address complex problems resulting in negative consequences will be more readily accepted by those impacted if they trust the solution reached is consistent with the values of the organization.

Is the innovator willing to adapt to new innovation processes rather than relying upon the entrenched processes of the past? When the need for a new innovation process arises, those who can self manage and correct course will earn the trust of those involved in the process. The honest acknowledgement of a need to break with the practices of the past is critical to building self confidence, as well as developing the relationships necessary to affect a positive result.

Is the innovator willing to quickly admit to and correct misjudgements? No other self management characteristic is as important in the development of emotional intelligence behaviours as the ability to openly admit to mistakes. Mistakes make emotionally intelligent human beings stronger and give them the opportunity to truly connect with others in honesty and humility.

Innovation Action Steps: It is useful for innovators to recall a complex and important innovation implemented without involving others. Was there a negative outcome? Did the innovation decrease the level of trust others have in the innovator? How could others have been involved in the innovation process? It is also helpful here to identify what actions could have been taken to develop the innovation skills of someone else. In replaying a scenario when an innovator failed to acknowledge and correct a misjudgement, what consequences or impacts did that failure cause? How could the scenario have played out differently if the individual had openly acknowledged and corrected the mistake?

\section{Application of relationship management skills}

Conflict, communication and relationship management are all inextricably linked to the innovation process. Innovators should consider the following questions and actions in the effort to more fully develop the relationship management skill set.

Are solutions viewed as a means of developing or furthering relationships with those with whom the innovator works? Relationships are based upon communication and trust, and the emotionally intelligent individual looks at every innovation circumstance as an opportunity to develop or improve the relationship with another person.

How does the innovator communicate with others engaged in the innovation process? This aspect of relationship management requires a regular and consistent method of communication that reinforces the role of each person in the innovation process. When a problem has been delegated it remains critical to support that delegation in all communications.

Are communications in conflict situations direct and forthright? Emotional intelligence is exhibited in conflict settings by seeking first to understand the position and feelings of the other person [57]. Thus in circumstances of conflict, the emotionally intelligent innovator listens more than they speak and seeks opportunities to learn the opinions of others. Being direct about conflicting views is important to demonstrate honesty, and exhibiting compassion in moments of tension develops the trust necessary to foster long-term relationships.

What are the innovator's attributes in managing conflict? The emotionally intelligent response in moments of conflict requires an 
examination of one's own emotions. The emotionally intelligent innovator manages volatility by expressing compassion while exhibiting and furthering the values of the organization in the innovation process [56].

Innovation Action Steps: While reflecting on an innovation that created a large amount of conflict or controversy, recall the methods used to communicate the innovation. How could the process have been handled to lessen the conflict or controversy? It is most important to identify those who may have been negatively impacted, and inquire of those individuals how the process should have been handled from their perspective.

\section{Conclusions}

Innovation has become the battle cry for organizations who desire to thrive and perpetuate their missions. In the highly competitive environment in which organizations, both for-profit and not-forprofit, must survive, the application of emotional intelligence skills can assist in enhancing the quality of innovation and innovation processes. We have shown that the behaviours and competencies associated with emotional intelligence (Self Awareness, Self Management, Social Awareness and Relationship Management) are meaningful tools in the innovation development and management process. Specifically, innovators who are self aware and can accurately and honestly assess their strengths in comparison to others in the organization have the advantage of leveraging the attributes of others in the innovation process. Additionally, the ability to assess the potential emotional outcomes and reactions to innovations can increase the probability of a more positive outcome. Most organizations are approaching innovation in a team environment, recognizing that the process of building and maintaining relationships is inherently human and requires an emotional perspective and while time consuming, will generate better innovations and creative solutions. Moreover, problems requiring innovative solutions often generate conflict, and the ability to manage that conflict involves an emotional intelligence skill that can determine the ultimate success of the innovation process. Thus, the practical application of emotional intelligence skills and behaviours can enhance not only the innovation itself but also the processes associated with innovation.

\section{References}

1. Goleman D (2001) Emotional intelligence: perspectives on a theory of performance. In The Emotionally Intelligent Workplace. San Francisco, JosseyBass, California.

2. Boyatzis R, Goleman D, Rhee K (2000) Clustering competence in emotional intelligence: insights from the Emotional Competence Inventory $(\mathrm{ECl})$. In Handbook of Emotional Intelligence. San Francisco: Jossey-Bass, California.

3. Stanovich K, West R (2000) "Individual differences in reasoning: implications for the rationality debate". Behavioral and Brain Sciences 23: 645-665.

4. Bai Nina (2008) "IBM to build thinking computers modeled on the brain Discover Magazine (last accessed February 17, 2014).

5. Velasquez Juan D (1998) "Modeling Emotion-Based Decision-Making". In proceedings of AAAl fall symposium emotional \& intelligent: the tangled knot of cognition.

6. Lerner J, Shonk K (2010) "How anger poisons decision making". Harvard Business Review $88: 26$

7. Damasio A (1994) Descartes' Error: Emotion, Reason and the Human Brain Gosset/Putnam, New York.

8. Simon HA (1967) "Motivation and emotional controls of cognition". Psychological Review 74: 29-39.

9. Simon HA (1971) "Designing organizations for an information-rich world. In Computers, Communication and the Public Interest, John Hopkins Press: Baltimore, Maryland.
10. Mayer JD, Salovey P, Caruso DR (2008) "Emotional intelligence: new ability or eclectic traits". American Psychologist 63: 503-517.

11. Thorndike RK (1920) “Intelligence and its uses”. Harpers Magazine 140: 227-235.

12. Bar-On R (2006) The Bar-On model of emotional social intelligence (ESI)" Psicothema, 18: 13-25.

13. Payne WL (1983/1986) "A study of emotion: developing emotional intelligence self integration; relating to fear, pain and desire". Dissertation Abstracts International 47:203A.

14. Salovey P, Mayer J (1990) "Emotional intelligence". Imagination, Cognition and Personality 9: 185-211.

15. Bradberry T, Greaves J (2003) The Emotional Intelligence Quickbook Talentsmart. San Diego, California.

16. Salovey P, Grewal D (2005) "The science of emotional intelligence". Current Directions in Psychological Science 14: 281-285.

17. Petrides KV, Pita R, Kokkinaki F (2007) "The location of trait emotional intelligence in personality factor space". British Journal of Psychology 98: 273289

18. Goleman D (1995) Emotional Intelligence. Bantam Books: New York.

19. Goleman D (1998) "What makes a leader”. Harvard Business Review 76: 93-102.

20. Dulewicz V, Higgs M, Slaski M (2003) Measuring emotional intelligence: content construct and criterion-related validity. Journal of Managerial Psychology 18: 405-420.

21. Brackett MA, Warner RM, Bosco JS (2005) Emotional intelligence and relationship quality among couples. Personal relationships 12: 197-212.

22. Sue-Chan C, Latham GP (2004) The situational interview as a predictor of academic and team performance: A study of the mediating effects of cognitive ability and emotional intelligence. International Journal of Selection and Assessment 12: 312-320.

23. Welch J (2003) The best teams are emotionally literate. Industrial and Commercial Training 35: 168-170.

24. Rapisarda BA (2002) The impact of emotional intelligence on work team cohesiveness and performance. International Journal of Organizational Analysis 10: 363-379.

25. Sardo S (2004) Learning to display emotional intelligence. Business Strategy Review 15: 14-17.

26. Chaudhry AA, Usman A (2011) An investigation of the relationship between employees emotional intelligence and performance. African Journal of Business Management 5: 3556-3562.

27. Langhorn S (2004) How emotional intelligence can improve managemen performance. International Journal of Contemporary Hospitality Management 16: 220-230.

28. Hess JD, Bacigalupo AC (2010) The emotionally intelligent leader, the dynamics of knowledge-based organizations and the role of emotional intelligence in organizational development. On the horizon 18: 222-229.

29. Rosete D, Ciarrochi J (2005) Emotional intelligence and its relationship to workplace performance outcomes of leadership effectiveness. Leadership \& Organization Development Journal 26: 388-399.

30. Van Rooy DL, Viswesvaran C (2004) Emotional intelligence: A meta-analytic investigation of predictive validity and nomological net. Journal of Vocational Behavior 65: 71-95.

31. Cavallo K, Brienza D (2006) Emotional competence and leadership excellence at Johnson \& Johnson. Europe's Journal of Psychology.

32. Luskin F, Aberman R, DeLorenzo A(2005) The training of emotional competence in financial advisors. Issues in Emotional Intelligence.

33. Bachman J, Stein S, Campbell K, Sitarenios G (2000) Emotional intelligence in the collection of debt. International Journal of Selection and Assessment 8 : 176-182.

34. Oginska-Bulik N (2005) Emotional intelligence in the workplace: Exploring its effects on occupational stress and health outcomes in human service workers. International Journal of Occupational Medicine and Environmental Health 18: 167-175. 
Citation: Hess JD (2014) Enhancing Innovation Processes through the Application of Emotional Intelligence Skills. Review Pub Administration Manag 2: 143. doi: 10.4172/2315-7844.1000143

35. Carmeli A (2003) The relationship between emotional intelligence and work attitudes, behavior and outcomes: An examination among senior managers. Journal of managerial Psychology 18: 788-813.

36. Kernbach S, Schutte NS (2005) The impact of service provider emotional intelligence on customer satisfaction. Journal of Services Marketing 19: 438-444.

37. Taylor CA, Taylor JC, Stoller JK (2008) "Exploring leadership competencies in established and aspiring leaders: an interview-based study". Journal of General Internal Medicine 23: 748-754.

38. Wang YS, Huang TC (2009) "The relationship of transformational leadership with group cohesiveness and emotional intelligence". Social Behavior and Personality 37: 379-392.

39. Antonakis J, Ashkanasy NM, Dasborough MT (2009) Does leadership need emotional intelligence? The Leadership Quarterly 20: 247-261.

40. Dasborough MT, Ashkanasy NM (2002) "Emotion and attribution of intentionality in leader-member relationships". The Leadership Quarterly 13: 615-634.

41. Zhou J, George JM (2003) "Awakening employee creativity: The role of leader emotional intelligence”. The Leadership Quarterly 14: 545-568.

42. Sevdalis, Nick, Petrides KV, Harvey Nigel (2007) "Trait emotional intelligence and decision related emotions". Personality and Individual Differences 42: 1347-1358.

43. Mellers BA, Schwartz A, Ritov I (1999) "Emotion-based choice". Journal of Experimental Psychology 128: 1-14

44. Winter KA, Kuiper NA (1997) "Individual differences in the experience of emotions". Clinical Psychology Review 17: 791-821.

45. Hess JD, Bacigalupo AC (2011) Enhancing decisions and decision-making processes through the application of emotional intelligence skills. Management Decision 49: 710-721.

46. Jordan PJ, Ashlea CT (2004) "Managing emotions during team problem solving: emotional intelligence and conflict resolution". Human Performance 17: 195-218.
47. Druskat VU, Wolff SB (2001 March) "Building the emotional intelligence of groups". Harvard Business Review: 81-90.

48. Jordan PJ, Ashkanasy NM, Hartel CEJ, Hooper G (2002) “Workgroup emotional intelligence: scale development and relationship to team process effectiveness and goal focus". Human Resource Management review 12: 195-214.

49. Fenwick T (2003) "Examining workplace learning in new enterprises". The Journal of Workplace Learning 15: 123-132.

50. Park J (2005) "Fostering creativity and productivity through emotional literacy: the organizational context". Development and learning in Organizations 19: 5-7.

51. Suliman AM, Al-Shaikh FN (2007) "Emotional intelligence at work: links to conflict and innovation". Employee Relations 29: 208-220.

52. Yuvaraj S, Srivastava N (2007) "Are innovative managers emotionally intelligent? Journal of Management Research 7: 169-178.

53. Miller Elizabeth G (2009) "Understanding emotional reactions for negative services: the impact of efficacy beliefs and stage in process". Journal of Service Research 12: 87-89.

54. Tannenbaum R, Schmidt, Warren $F(1958,1973)$ "How to choose a leadership pattern". Harvard Business Review, May-June.

55. Vroom Victor H, Yetton Phillip W (1973) Leadership and Decision Making University of Pittsburgh Press, Pittsburgh, Pennsylvania.

56. Tsai Ming-Hong, Young, Maia J (2009) "Anger, fear and escalation of commitment". Cognition and Emotion-Online Version.

57. Huy Quy N (1999) "Emotional capability, emotional intelligence and radical change". Academy of Management Review 24: 325-345.

58. Bazerman M, Malhorta D (2006) "It's not intuitive: strategies for negotiating more rationally". Negotiation.

59. Mayer J, Caruso D (2002) "The effective leader: understanding and applying emotional intelligence". Ivey Business Journal, November-December, Reprint \# 9B02TF10. 